Enferm Bras 2021;20(6):732-49

Doi: $10.33233 /$ eb.v20i6.4675

\title{
ARTIGO ORIGINAL \\ Vivências e percepções sobre a sexualidade na terceira idade
}

Amanda Costa Lima*, Jessica de Almeida Rodrigues Alves*, Bianca Machado Ferreira**, Tiffany Pavelkonski da Silva**, Bruna Maria Pereira dos Santos**, Rebeca Costa dos Reis**, Vanessa Alvarenga Pegoraro, M.Sc. ${ }^{* * *}$

${ }^{\star}$ Enfermeira egressa do UNICEUB, ${ }^{* *}$ Estudante de graduação Enfermagem do UNICEUB, ${ }^{* * * P r o f e s s o r a ~ A s s i s t e n t e ~ d o ~ C u r s o ~ d e ~ E n f e r m a g e m ~ F A C E S / U N I C E U B ~}$

Recebido em 23 de março de 2021; Aceito em 29 de novembro de 2021.

Correspondência: Vanessa Alvarenga Pegoraro, FACES/CEUB, 707/907 Campus Universitário, SEPN Asa Norte, 70790-075 Brasília DF

\author{
Amanda Costa Lima: amanda.farias.c@hotmail.com \\ Jessica de Almeida Rodrigues Alves: jessiica.rodrigues10@gmail.com \\ Bianca Machado Ferreira: bianca.machado2012@sempreceub.com \\ Tiffany Pavelkonski da Silva: tiffany.ps@sempreceub.com \\ Bruna Maria Pereira dos Santos: brunamariaps@hotmail.com \\ Rebeca Costa dos Reis: rebeca.c.d.reis@gmail.com \\ Vanessa Alvarenga Pegoraro: vanessa.pegoraro@ceub.edu.br
}

\section{Resumo}

Introdução: Com o constante processo de envelhecimento da população, a vida sexual da terceira idade também sofreu modificações, mostrando que o idoso é um gerador de novas facetas sexuais. Objetivo: Analisar de que forma a sexualidade é compreendida e vivenciada pelos idosos do Distrito Federal (DF). Métodos: Trata-se de uma pesquisa de campo descritiva, de abordagem quantitativa realizada no ano de 2020. Resultados: Participaram do estudo 411 idosos que ao serem questionados sobre se sentirem à vontade para falar sobre sexualidade, $79,81 \%$ disseram se sentir bem; quando questionados se é importante ter conhecimento sobre sexualidade, 71,29\% responderam que sim; sobre desejos atuais $71,78 \%$ disseram ter; sobre ter vida sexual ativa $61,07 \%$ possuem. Conclusão: Portanto, podemos concluir que, apesar das modificações fisiológicas, os idosos estão se adaptando e se reinventando nas práticas 
sexuais. Os mesmos entendem a importância da sexualidade nessa fase da vida e pela busca do prazer pessoal.

Palavras-chave: idoso; sexualidade; qualidade de vida.

\section{Abstract}

\section{Livingness and perceptions about sexuality in the third age}

Introduction: With the constant aging process of the population, the sexual life of the elderly has also undergone changes, showing that the elderly is a generator of new sexual aspects. Objective: To analyze how sexuality is understood and experienced by the elderly in the Federal District (DF). Methods: This is a descriptive field research, with a quantitative approach made in 2020. Results: Participated in the study 411 elderly people who, when asked about feeling comfortable talking about sexuality, $79.81 \%$ said they feel good; when asked if it is important to have knowledge about sexuality, $71,29 \%$ answered yes; about current desires, $71.78 \%$ said they had; about having an active sex life, $61.07 \%$ had it. Conclusion: Therefore, we can conclude that despite the physiological changes, the elderly are adapting and reinventing themselves in sexual practices. They understand the importance of sexuality at this stage of life and the pursuit of personal pleasure.

Keywords: elderly; sexuality; quality of life.

\section{Resumen}

\section{Experiencias y percepciones de la sexualidad en la vejez}

Introducción: Con el constante proceso de envejecimiento de la población, la vida sexual de los adultos mayores también ha sufrido cambios, demostrando que el adulto mayor es un generador de nuevas facetas sexuales. Objetivo: Analizar cómo la sexualidad es entendida y experimentada por los adultos mayores del Distrito Federal (DF). Métodos: Se trata de una investigación de campo descriptiva, con enfoque cuantitativo celebrado en 2020. Resultados: Participaron del estudio 411 ancianos que, cuando se les preguntó sobre sentirse cómodos hablando de sexualidad, 79,81\% dijeron sentirse bien; cuando se les preguntó si es importante tener conocimientos sobre sexualidad, 71,29\% respondieron que sí; sobre deseos actuales, 71,78\% dijeron que tenían; acerca de tener una vida sexual activa, 61,07\% tiene. Conclusión: Por tanto, podemos concluir que, a pesar de los cambios fisiológicos, los adultos mayores se están adaptando y reinventándose en las prácticas sexuales. Entienden la importancia de la sexualidad en esta etapa de la vida y la búsqueda del placer personal.

Palabras-chave: anciano; sexualidad; calidad de vida. 
Introdução

No decorrer dos anos, foi possível observar uma mudança demográfica em decorrência da longevidade devido aos avanços da medicina e da tecnologia, que criaram novos meios para o cuidado da saúde e da qualidade de vida (QV), bem como pelo investimento em políticas públicas voltadas para o processo de envelhecimento [1].

A Organização Mundial da Saúde (OMS) define como idoso aquela pessoa com mais de 60 anos, sendo possível observar o ritmo de crescimento da população idosa mundialmente e, principalmente, no Brasil, onde houve uma modificação na pirâmide etária [2].

O Brasil está envelhecendo. Segundo dados do Instituto Brasileiro de Geografia e Estatística (IBGE), "em 2000 a população idosa com mais de 60 anos era de 14,5 milhões de pessoas, um aumento de $35,5 \%$ ante os 10,7 milhões em 1991 . Hoje, esse número ultrapassa os 29 milhões e a expectativa é que, até 2060, suba para 73 milhões com 60 anos ou mais, o que representaria um aumento de 160\%." Diante dessa perspectiva, o país terá mais idosos devido uma redução gradativa da fecundidade [3].

Dessa forma, torna-se essencial compreender o envelhecimento como um processo natural onde as modificações biológicas, psicossociais e culturais são inevitáveis, porém em nada afetam no desejo e na satisfação sexual [4]. A OMS define a sexualidade como a porção plena e total do conjunto de qualidades que define a individualidade do ser humano, é composta através da vivência e trocas de experiências na sociedade. É motivadora das relações interpessoais e dos sentimentos que influencia nossa maneira de viver, pensar, agir e sentir [5].

Com o constante e crescente processo de envelhecimento da população, a sexualidade na terceira idade também sofreu modificações, mostrando que o idoso é um gerador de novas facetas sexuais. O conhecimento relacionado a mesma ganhou evidência em nossa sociedade contemporânea devido às mudanças dos padrões sociais e no que diz respeito às individualidades e peculiaridades de cada pessoa [6].

À vista disso, a sexualidade deve ser entendida como fator fundamental em qualquer época da vida, sendo ímpar a cada pessoa. Ela remete diversos sentimentos físicos e emocionais e é construída ao longo da vida, sofrendo influência do meio histórico, social e cultural, de acordo com os aspectos individuais e psicológicos de cada um. Não diz respeito somente aos órgãos genitais e se apresenta de diversas formas, sendo versátil e indo além da necessidade fisiológica, representando o desejo. Porém, notam-se dificuldades de aceitação da sexualidade durante o processo de envelhecimento, as quais são resultantes, principalmente, da inexistência de informação e da convicção de que a sexualidade está reduzida aos órgãos genitais e à reprodução. 
A educação da atual geração de idosos foi repressora e restritiva, sem espaço para conversas entre pais e filhos ou para se falar sobre o assunto [7].

Nesse contexto, a sexualidade na velhice se torna um tema insuficientemente estudado, que pode ser descrita como o resultado das incontáveis metamorfoses socioculturais incentivadas pelo conhecimento científico e espiritual e que ao decorrer do processo histórico social tradicional e dos tempos atuais compreenderam e deram nova formulação aos conceitos de sexualidade e suas diversidades, de forma que a mesma esteve sempre vista como uma atividade aceita e, ao mesmo tempo, censurável. Logo, sentir desejo e ser idoso, numa sociedade que cultua a beleza e a jovialidade de forma exagerada, é extremamente maçante e significa enfrentar diariamente grandes batalhas e juízo de valores preconcebidos pela sociedade [8].

Durante o processo histórico, ergueu-se a crença de que a sexualidade do idoso deveria partir da masculinidade. Logo, as mudanças durante o processo de envelhecimento trariam consigo a diminuição ou até mesmo a cessação do desejo sexual e, ao se desafiar essa ideia, o indivíduo padeceria com as dificuldades e até mesmo com o desgosto que o peso dos anos propõe ao corpo físico [9].

Dessa maneira, o ato sexual fica restrito em uma escala de tempo, deixando implícito que os idosos devem ser insexuados, pois o intuito principal é a procriação. Os períodos da vida humana, ao longo da história, delimitam a expressão da sexualidade, alegando o serviço do controle social e da hierarquização dos papeis da sociedade atual, deixando claro que o idoso deve se comportar de maneira íntegra, sem vida sexual ativa e passa a atuar em prol do meio em que vive com certa censura. Além disso, foi construído o conceito de que o envelhecimento e a sexualidade devem ser vistos pela ótica heterossexual, renunciando assim as diferentes vertentes da sexualidade no processo de envelhecimento [10].

A modernidade traz consigo diversas maneiras da população idosa se reinventar, inclusive nas práticas sexuais. Por vezes, o preconceito e a complexidade de se criar medidas profiláticas em meio a esse público, especialmente no que se refere ao uso da camisinha, acaba sendo um complicador, pois observa-se que existem poucas campanhas voltadas para a terceira idade. Dessa forma, traz à tona a questão de que os mesmos estão mais propensos a práticas de sexo inseguro e consequentemente à contaminação pelas infecções sexualmente transmissíveis (ISTs) e HIV/AIDS [11].

A desmistificação do sexo associado aos avanços na indústria farmacêutica e da medicina permitiram o prolongamento da vida sexual ativa. Com isso, a possibilidade de um idoso se contaminar é real e continuar a renegar a sexualidade nessa população significa exposição a doenças e uma assistência quebrada e ineficaz [11]. 
Diante disso, o interesse pela temática de estudo surge das discussões acadêmicas diante dos fatos amplamente divulgados na literatura. Nesse contexto, debatia-se sobre sexualidade, preconceitos e conhecimentos acerca do assunto. Desse modo, questiona-se: "Como a sexualidade é vista e vivenciada na terceira idade?". Com vistas a respondê-la, o presente estudo tem como objetivo descrever de que forma a sexualidade é compreendida e vivenciada pelos idosos do Distrito Federal-DF?". Esta pesquisa mostra-se relevante, uma vez que se propõe discutir sobre um assunto ainda estigmatizado para a população como um todo.

\section{Métodos}

Trata-se de um estudo transversal, descritivo de abordagem quantitativa, que avaliou a maneira como a sexualidade é retratada e vivenciada na terceira idade. Foi realizado com os idosos do Distrito Federal (DF) e a coleta de dados ocorreu entre os dias 02/08/2020 e 31/08/2020.

Os critérios de inclusão adotados foram: pessoas com faixa etária superior a 60 anos de idade de ambos os sexos, que aceitaram o Termo de Consentimento Livre e Esclarecido (TCLE) e ser domiciliado no DF. Quanto aos critérios de exclusão, foram excluídos os participantes que não se enquadraram na faixa etária e que não responderam todas as perguntas dos questionários.

Os participantes receberam um link para responderem o questionário, através dos WhatsApp pessoais, o formulário foi também aplicado nos idosos que frequentavam o laboratório em que a pesquisadora trabalhava. Ao abrir o link, é apresentado o Termo de Consentimento Livre e Esclarecido (TCLE) para participar da pesquisa de forma anônima e voluntária, contendo a informação do Comitê de Ética quanto aos riscos, objetivos e privacidade da pesquisa.

Foram realizadas entrevistas com a aplicação de dois instrumentos de pesquisa. Uma para conhecer os aspectos sociodemográficos, econômicos e educacionais e o outro foi um instrumento específico sobre sexualidade, na qual as perguntas abordaram as práticas, a frequência, os desejos, dentre outras. Os dados foram coletados por meio de um instrumento elaborado pelos autores a qual foi reformulado para a aquisição das informações necessárias [7].

A realização da coleta de dados efetuou-se pelo Google Forms, uma ferramenta online do Google utilizada para a realização de formulários, na qual suas respostas foram colocadas em uma planilha e os dados convertidos para Excel. 
A população de idosos do DF é de 346 mil, que constitui a amostra da pesquisa e para ter $95 \%$ de confiança nos resultados da mesma precisaríamos de 384 respostas, mas tivemos no total 411 [3].

A Organização dos dados adquiridos foi realizada utilizando o software Microsoft Excel $2010 \AA$, pertencente o Pacote Microsoft Office $2010 \AA$ for Windows $\AA$. Foram desenvolvidas tabelas explicativas para análise descritiva com o cálculo dos percentuais e médias.

Os procedimentos adotados nesta pesquisa obedecem aos Critérios da Ética em Pesquisa com Seres Humanos conforme Resolução nํ․466/12 do Conselho Nacional de Saúde com aprovação do Comitê de Ética em Pesquisa do UniCEUB sob protocolo CAAE no 33810420.0.0000.0023 e Número do Parecer: 4.169.049.

\section{Resultados e discussão}

Na tabela I é apresentado o perfil sociodemográfico dos idosos entrevistados.

Tabela I - Distribuição das variáveis sociodemográficas dos idosos do Distrito Federal, $2020(n=411)$

\begin{tabular}{lll}
\hline Variável & Quantidade & Representatividade (\%) \\
\hline Idade & & \\
\hline 60 a 69 anos & 121 & 29,44 \\
70 a 79 anos & 165 & 40,15 \\
80 anos ou mais & 125 & 30,41 \\
Sexo & & \\
\hline Feminino & 190 & 46,23 \\
Masculino & 221 & 53,77 \\
\hline Estado civil & & \\
\hline Casado(a) & 80 & 19,46 \\
Separado(a) & 122 & 29,68 \\
Solteiro(a) & 160 & 38,93 \\
Viúvo(a) & 49 & 11,92 \\
\hline Escolaridade & & \\
\hline Nenhum & 6 & 1,46 \\
1 a 4 anos & 48 & 11,68 \\
5 a 8 anos & 161 & 39,17 \\
9 anos ou mais & 196 & 47,69 \\
Religião & & \\
\hline Católica & 64 & 15,57 \\
Espírita & 42 & 10,22 \\
Evangélica & 185 & 45,01 \\
Outras & 19 & 24,57 \\
Não possui & 101 & 4,62 \\
\hline Fonte: Produço & & \\
\hline
\end{tabular}

Fonte: Produção dos autores do estudo, 2020.

Participaram do estudo 411 idosos, sendo maior preponderância da variável sexo masculino representando (53,77\%) e feminino com 46,23\%. Uma pesquisa realizada no Paraná obteve resultados semelhantes quanto à predominância da participação masculina, onde os autores destacam que a sexualidade ainda é cercada de tabus, onde o mesmo é fruto de uma educação rigorosa e repressora, a qual deve 
partir somente dos homens e não das mulheres, onde as mesmas teriam apenas o papel de reprodução [12].

Em relação à faixa etária, foi analisada uma predominância da idade entre $70 \mathrm{e}$ 79 anos, somando 165 participantes (40,15\%). Quanto ao estado civil, prevalece o estado de solteiro, com 160 (38,93\%), seguido de 122 divorciado (a) (29,68\%), 80 casados $(19,46 \%)$ e 49 viúvos (11,92\%), portanto a grande maioria dos participantes viviam sem companheiro fixo. Durante uma pesquisa realizada no estado da Paraíba constatou-se que o quantitativo de idosos solteiros pode ser justificado devido à dificuldade em encontrar um parceiro na mesma faixa. A idade e o descontentamento com relacionamentos pregressos fazem com que os mesmos priorizem sua independência [13].

Em relação à escolaridade, 196 entrevistados alegaram ter 9 ou mais anos de estudo, representando (47,69\%), seguido de 161 entrevistados que estudaram de 5 a 8 anos, representando $(39,17 \%)$. Conforme um estudo realizado em Brasília, o número de idosos que ingressam na universidade tem demonstrado bastante expressividade, inclusive na região centro-oeste, relacionam isso à criação do Estatuto de Idoso, que deve garantir à pessoa idosa proteção da vida, de saúde, juntamente com políticas públicas que devem promover um envelhecimento saudável, com qualidade de vida, educação e dignidade [14,15].

Quanto à variável religião, predominou que 185 idosos (45,01\%) são evangélicos, seguido de católicos (15,57\%), espíritas (10,22\%) e 101 (4,62\%) não possuem religião.

Quando indagados sobre "se sentem à vontade para falar sobre sexualidade", conforme demonstrado na Figura 1,328 respondentes $(79,81 \%$ da população) declararam se sentir à vontade para falar sobre sexualidade.

Adicionalmente, foram observados três desvios relevantes em relação às informações sociodemográficas:

Nos desvios 1.1 e 1.3, referentes às variáveis "idosos que possuem entre 1 e 4 anos de estudo" e "idosos que declararam possuir outra religião (exclui-se católica, evangélica, espírita e não possuir)", os idosos se demonstraram menos à vontade para falar sobre sexualidade.

Constatou-se, em uma pesquisa realizada na cidade de Montes Claros/MG, que os idosos declaram que a moralidade cristã ainda é um fator significativo na vida dos idosos, a mesma tem grande influência no comportamento sexual, pois estabelece regras e cria tabus [16]. Ao longo de um estudo feito no estado da Bahia, os autores constataram que a sexualidade tem que ser tratada e abordada como algo comum, com o intuito de incitar práticas saudáveis de viver essa sexualidade, para que todo idoso possa ter o prazer de expor seu comportamento sexual [17]. 
Você se sente à vontade para falar sobre sexualidade?

$328 ; 80 \%$

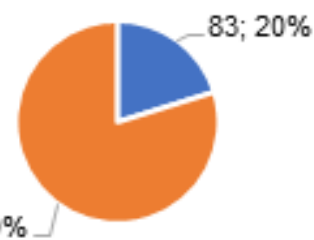

Desvio 1.2

Idosos que pertencem a religião espírita

$4 ; 10 \%$
- Não

$-\operatorname{Sim}$

Nao

$=\operatorname{Sim}$

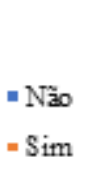

$38 ; 90 \%$

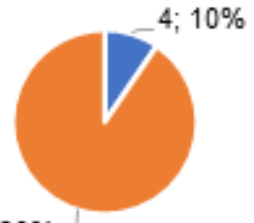

Desvio 1.1

Idosos que possuem entre 1 e 4 anos de estudo

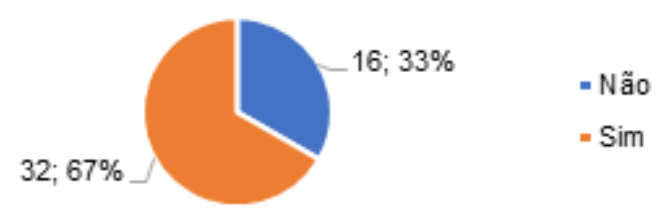

Desvio 1.3

Idosos que declararam possuir outra religião (exclui-se católica, evangélica, espírita e não possuir)

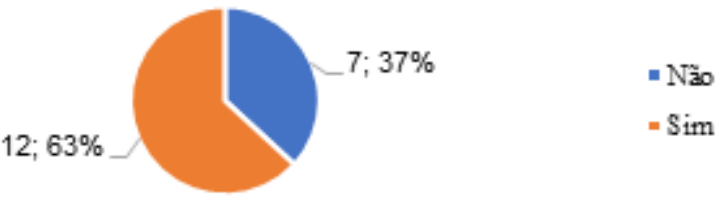

Fonte: Produção dos autores do estudo, 2020.

Figura 1 - Distribuição percentual e quantitativa dos idosos entrevistados em relação a se sentirem à vontade para falar sobre sexualidade

Ao serem questionados se "acreditavam que era importante ter conhecimento sobre sexualidade", conforme é possível observar na Figura 2, 293 respondentes (71,29\% da população) declararam achar importante que os idosos tenham conhecimento sobre sexualidade.

Foram observados quatro desvios relevantes em relação às informações sociodemográficas:

O desvio 2.1 mostra que idosos com menos escolaridade (máximo de 4 anos, incluindo aqueles que nunca estudaram) declararam não ser importante conhecimento sobre sexualidade.

Já nos desvios 2.2, 2.3 e 2.4, relacionado às variáveis escolaridade, estado civil e religião, evidencia-se que "Idosos com 9 ou mais anos de escolaridade", "Idosos casados atualmente ou viúvos" e "Idosos que pertencem à religião católica ou outras religiões (excluem-se evangélica, espírita e não possuir)", declararam julgar importante os conhecimentos sobre sexualidade. 
Você acha importante os idosos terem conhecimento sobre a sexualidade?

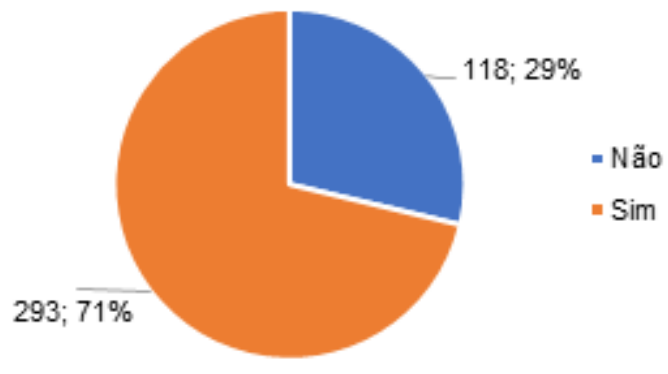

Desvio 2.4

Idosos que pertencem a religião católica ou outras.

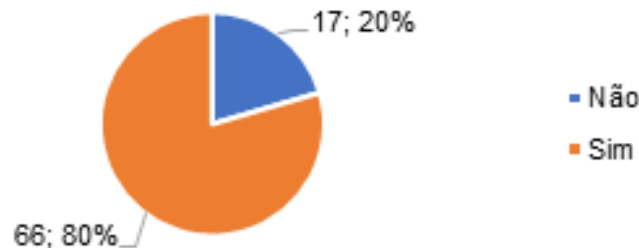

Desvio 2.1

Idosos com menos escolaridade, incluindo aqueles que nunca estudaram

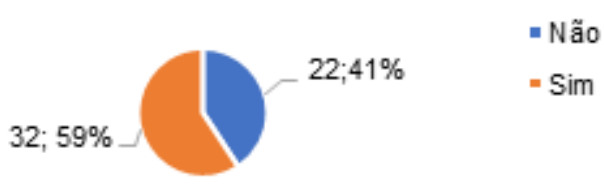

Desvio 2.2

Idosos com mais de 9 anos de escolaridade

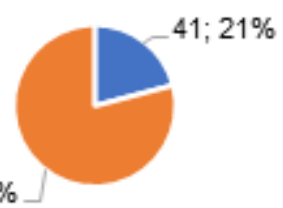

- Não

- Sim

$155 ; 79 \%$

Desvio 2.3

Idosos casados ou viúvos

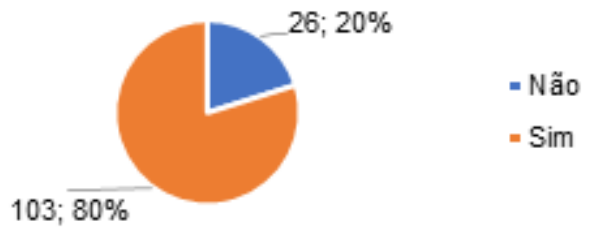

Fonte: Produção dos autores do estudo, 2020

Figura 2 - Distribuição percentual e quantitativa dos idosos entrevistados em relação à importância do conhecimento sobre sexualidade

O estudo determinou que as amostras estudadas julgaram como importante 0 conhecimento sobre a sexualidade. Na mesma direção, a pesquisa realizada no município de Recife/PE, constatou também que os idosos consideram importante tal conhecimento. Vale destacar que essa confirmação significa que os idosos estão cada vez mais interessados no assunto e solidifica que a falta de informação sobre o comportamento sexual no envelhecimento é fruto de uma educação preconceituosa que se baseia em modelos normativos e repressivos [18].

Quando indagados sobre se "teriam desejos sexuais atualmente", conforme demonstrado na figura 3, 295 respondentes (71,78\% da população) declararam possuir desejos sexuais nos dias atuais.

Complementarmente, foram observados quatro desvios relevantes em relação às informações sociodemográficas:

Podemos observar nos desvios 3.1, 3.2 e 3.4, referentes às variáveis estado civil, grau de instrução e religião, evidenciou que os "idosos viúvos", "idosos que possuem até 4 anos de estudos, incluindo aqueles que nunca estudaram" e "idosos que declararam pertencer à religião espírita" possuem menos desejo sexual nos dias atuais. 
Você tem desejo sexual nos dias atuais?

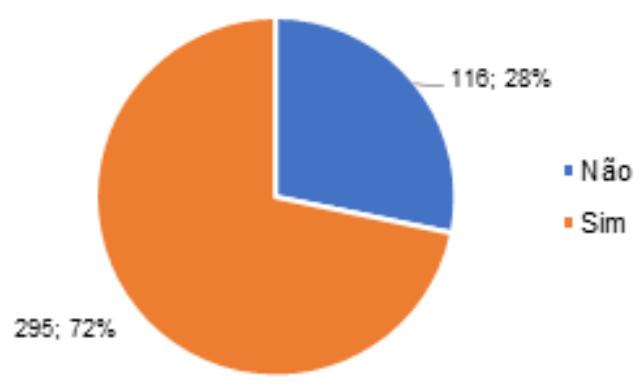

Desvio 3.4 idosos que declararam pertencer a religião espírita

$26 ; 62 \%$

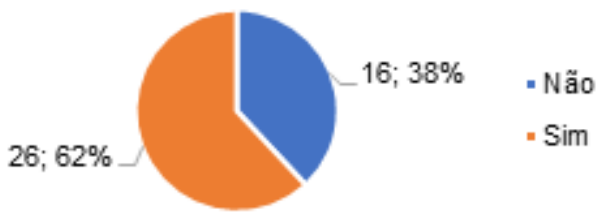

Desvio 3.1

idosos viúvos

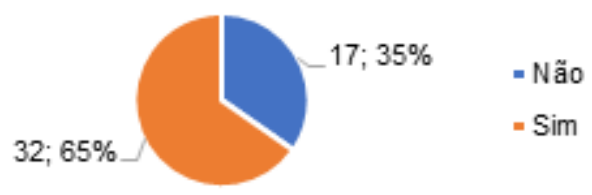

Desvio 3.2

idosos que possuem até 4 anos de estudo

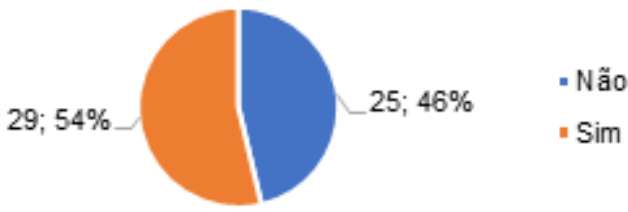

Desvio 3.3

idosos que possuem 9 ou mais anos de estudo

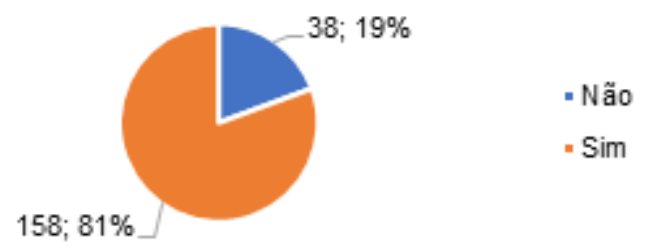

Fonte: Produção dos autores do estudo, 2020

Figura 3 - Distribuição percentual e quantitativa dos idosos entrevistados em relação a terem desejo sexual nos dias atuais

Já no desvio 1.3, idosos que possuem 9 ou mais anos de estudos demonstraram possuir mais desejo sexual na atualidade.

No decorrer dos anos, o desejo, o amor, a euforia e o carinho continuam presentes e são fundamentais na terceira idade, pois proporcionam satisfação e entusiasmo. A convicção de que envelhecimento e a falta de atividade sexual estão inevitavelmente ligados, infelizmente, de algum modo, exacerba a ignorância e o preconceito acerca da sexualidade da pessoa idosa, levando a um declínio na qualidade de vida dessa população. Devido à insciência e à imposição cultural, muitos idosos que ainda possuem desejo sexual às vezes se sentem constrangidos e envergonhados, simplesmente por cogitarem possuir prazer. Essas condutas criadas pela sociedade restringem o comportamento sexual aos jovens, logo, os idosos são vítimas de preconceitos, o que prejudica a sua qualidade de vida [19].

Quando questionados "sobre a vida sexual ativa", conforme demonstrado na figura 4,251 respondentes $(61,07 \%$ da população) declararam possuir a vida sexual ativa. 
Você tem vida sexual ativa?

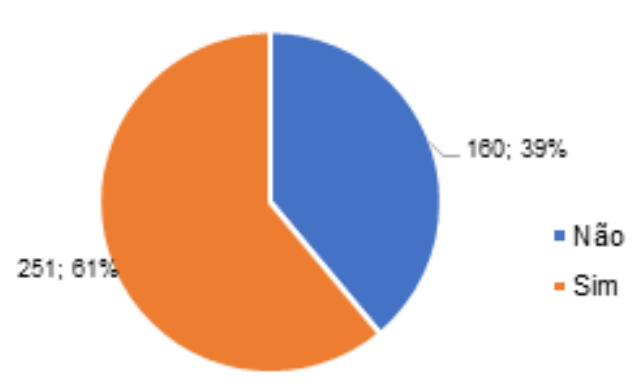

Desvio 4.4

idosos que declaram possuir outras religiões

$26 ; 70 \%$

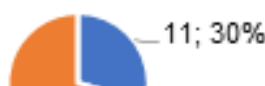

- Não

- Sim
Desvio 4.1

idosos cujo estado civil é separado/divorciado

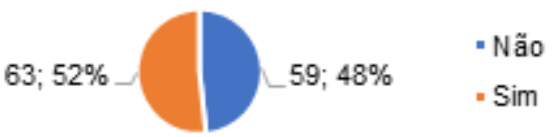

Desvio 4.2 idosos casados

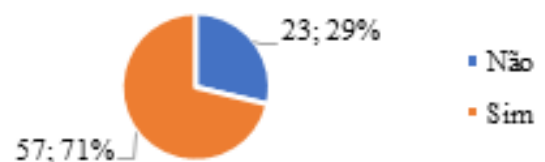

Desvio 4.3

idosos que possuem ate 4 anos de estudo, incluindo aqueles que nunca estudaram

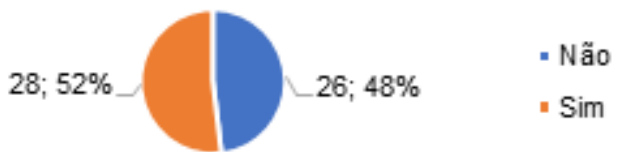

Fonte: Produção dos autores do estudo, 2020.

Figura 4 - Distribuição percentual e quantitativa dos idosos entrevistados em relação à atividade sexual

Nesse sentido, foram observados quatro desvios relevantes em relação às informações sociodemográficas:

Nos desvios 4.1, 4.3 e 4.4, referentes às variáveis: estado civil, escolaridade e religião, foi observado que "idosos cujo estado civil é separado/divorciado", "idosos que possuem até 4 anos de estudo, incluindo aqueles que nunca estudaram" e "idosos que declararam possuir outras religiões (excluem-se católicos, espíritas, evangélicos e ateus)" têm a vida sexual menos ativa.

Já no desvio 4.2, idosos cujo estado civil é casado demonstraram ter a vida sexual mais ativa, 57 pessoas declararam ser ativos sexualmente.

Assumir que o sexo se mantém na fase do envelhecimento implica pensar que os idosos também estão expostos às doenças relacionadas ao sexo desprotegido. Em uma pesquisa realizada com um grupo de convivências em Trindade/GO, observaram que os idosos não se identificam nessa situação de fragilidade, trazendo à tona a discussão do mito de que pessoas da terceira idade são seres assexuados [20]. A sociedade e os próprios profissionais de saúde raramente acreditam que pessoas da terceira idade possa ser atingidos por IST's, pois os consideram como sexualmente inativos deixando de detectar precocemente a doença [21]. 
Quando questionados sobre a forma mais utilizada para a prática sexual, conforme na figura 5, 133 respondentes (32,36\%) declararam que a forma de estimulação sexual mais utilizada é a penetração.

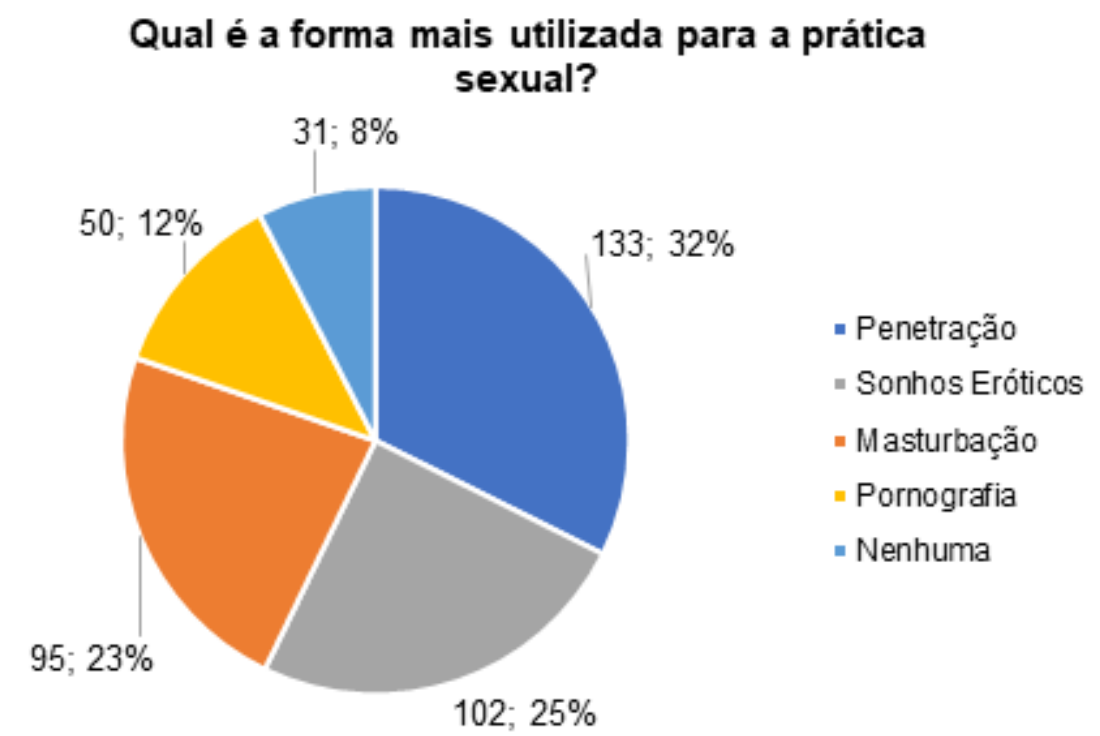

Fonte: Produção dos autores do estudo, 2020

Figura 5 - Distribuição percentual e quantitativa dos idosos entrevistados em relação à forma mais utilizada para estimulação

Embora as mulheres demonstrem ter vida sexual ativa, as mudanças fisiológicas decorrentes do envelhecimento acabam limitando 0 ato sexual. As, mulheres compreendem as mudanças sexuais devido à idade, mas é com a chegada da menopausa e suas modificações que surgem os primeiros problemas. O ressecamento e a dispareunia são os motivos mais citados, causando dor e atrapalhando a atividade sexual, promovendo o desinteresse e a redução do comportamento sexual. O processo de envelhecimento e seus efeitos não podem ser driblados, mas podem dar-se de maneira mais serena e saudável, desde que as mulheres com maior idade estejam cientes e prontas para as mudanças corporais [22].

Em relação ao questionamento sobre a "frequência de atividade sexual", é possível observar na figura 6 que 150 respondentes (36,50\%) declararam que sua frequência sexual é semanal.

Grande parte dos idosos são absolutamente capazes de ter relações sexuais e sentirem prazer, embora o ato em si seja designado por uma excitação mais lenta, porém satisfatória. Embora o corpo tenha sofrido modificações, o desejo sexual manteve-se intacto. Infelizmente, a sociedade considera que os idosos são seres assexuados, por compartilharem de um pensamento arcaico. No entanto, os dados do 
presente estudo revelam o antagonismo a tais opiniões errôneas quanto à sexualidade na terceira idade [23].

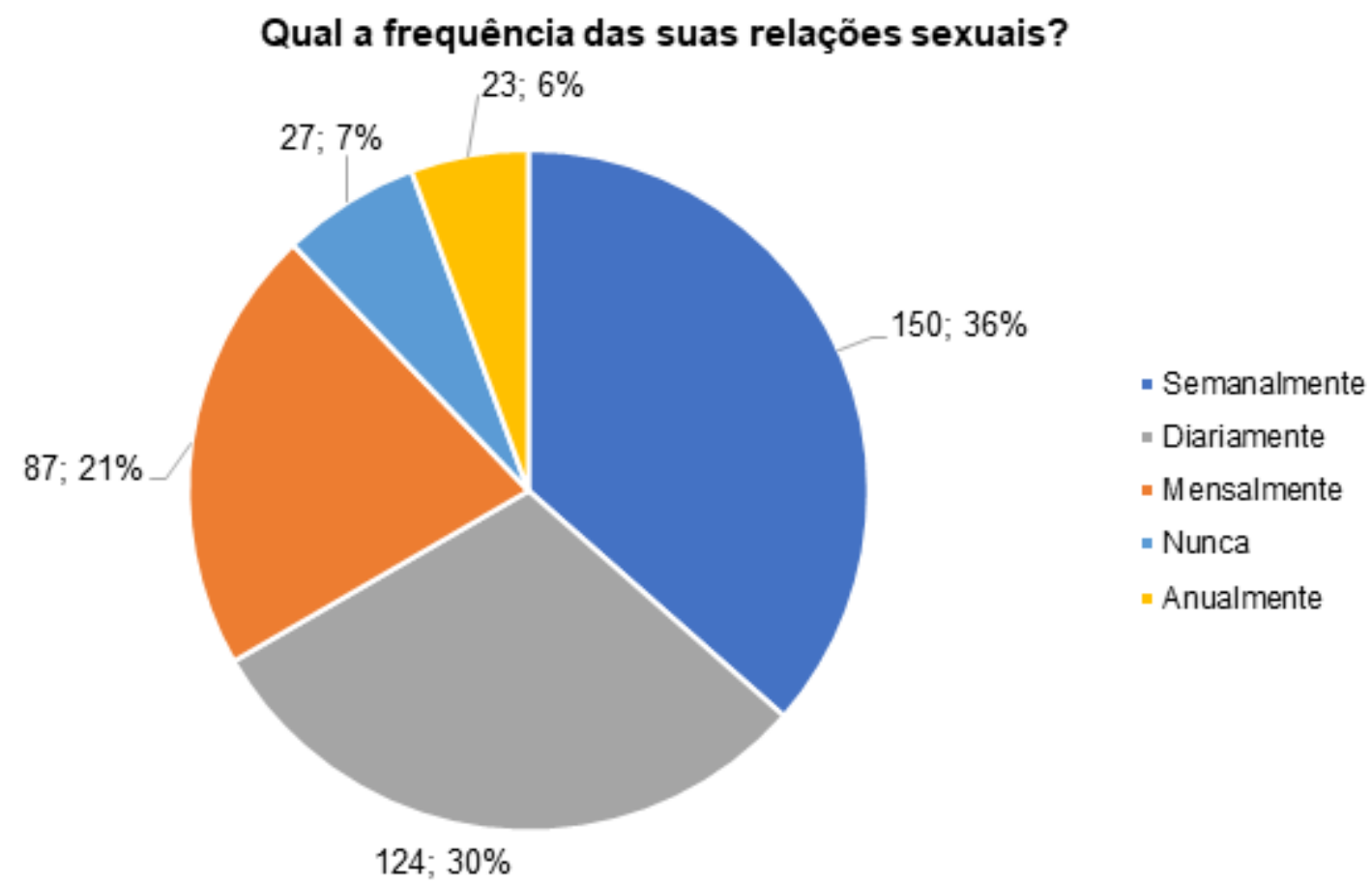

Fonte: Produção dos autores do estudo, 2020

Figura 6 - Distribuição percentual e quantitativa dos idosos entrevistados em relação à frequência das relações sexuais

Quando questionados sobre a "mudança sexual da juventude para a velhice", conforme figura 7, observa-se que apesar da pouca diferença entre os percentuais, a maior preponderância foi de 211 respondentes (51,34\%) que declararam encarar como pior a mudança sexual da juventude para a velhice.

Como você vê a mudança sexual da juventude para a velhice?

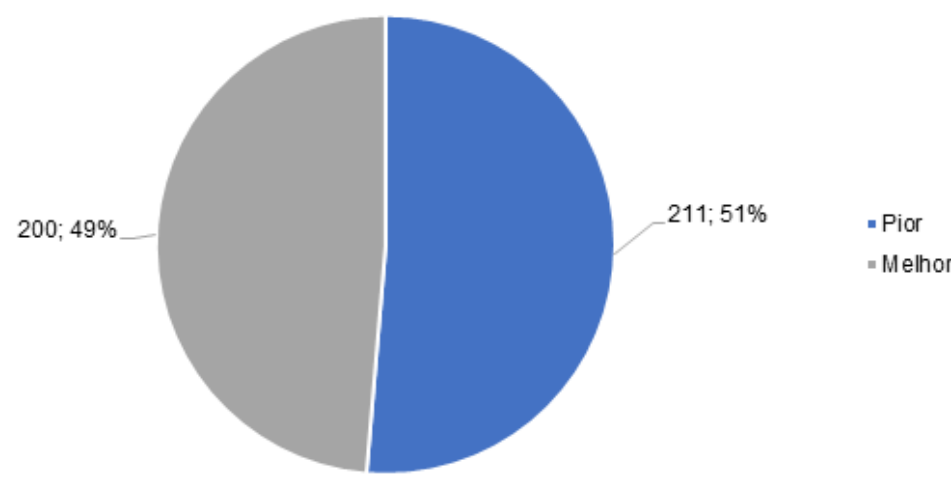

Fonte: Produção dos autores do estudo, 2020

Figura 7 - Distribuição percentual e quantitativa dos idosos entrevistados em relação à mudança sexual da juventude para a velhice 
Os elementos culturais influenciam no modo de enxergar o envelhecimento, logo, interfere na forma como o idoso vai se estabelecer nesse meio. As mudanças fisiológicas influenciam diretamente na resposta sexual do idoso, levando esses idosos a expressarem a relação por outros meios que não seja a penetração. As mudanças fisiológicas atrapalham e limitam a função sexual, fazendo com que os idosos tenham uma visão negativa dessa fase da vida [10].

A sexualidade é muito mais do que o ato em si, diz respeito a uma função humana com dimensão social e psicológica, que não é determinada apenas pelo instinto. Embora o sexo se manifeste de maneiras diferentes em cada fase da vida, ele tem um comportamento duradouro e habilidades progressivas desde o nascimento até a morte, o que mostra que o desejo sexual permanece o mesmo e o desejo de intimidade e afeto persiste nos anos posteriores [24].

Quando abordados sobre a importância do sexo, como é possível observar na figura 8, 239 respondentes $(58,15 \%)$ declararam considerar o sexo muito importante.

\section{Qual a importância do sexo para você?}

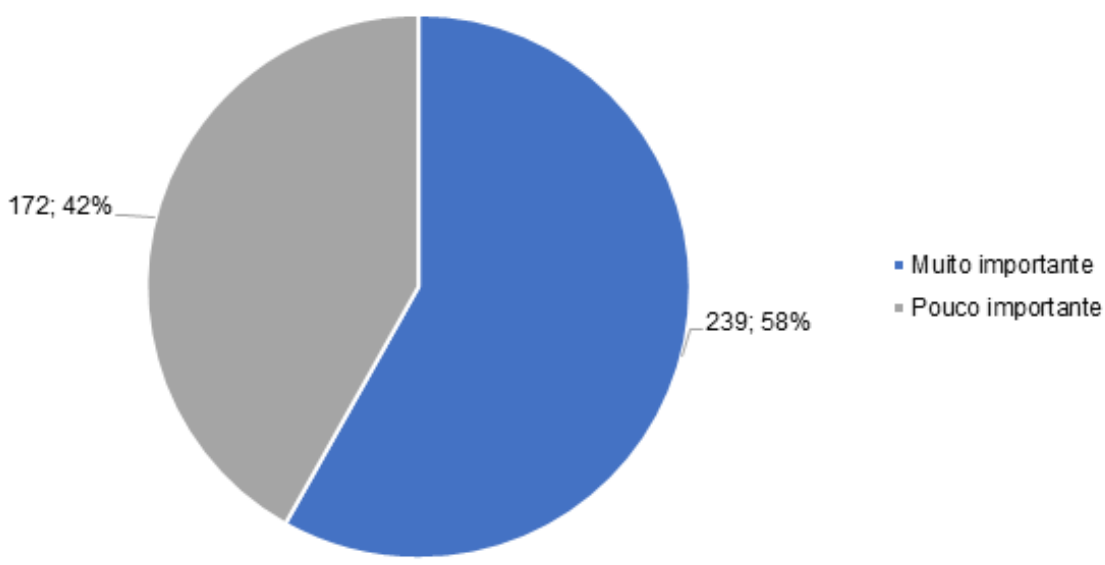

Fonte: Produção dos autores do estudo, 2020

Figura 8 - Distribuição percentual e quantitativa dos idosos entrevistados em relação à importância do sexo

Como observado nesta pesquisa, o sexo é um elemento de grande importância, podendo ser expressado através dos gestos, conversas e atitudes, sendo ímpar a cada indivíduo. Em conformidade com a pesquisa realizada no estado da Paraíba, os idosos confirmaram que o ato é importante, comprovando que a continuidade da vida sexual garante o bem-estar físico e psicológico, além de ajuda a reduzir problemas de saúde mental e físicos que estão relacionados com o envelhecimento [13].

Em virtude dos fatos mencionados de que a sexualidade continua sendo parte integrante da qualidade de vida dos idosos, uma compreensão por parte dos próprios 
idosos e pelos profissionais de saúde pode contribuir para futuras pesquisas, ações de educação em saúde, assim como para as políticas públicas voltadas à população idosa que aumenta com a longevidade.

\section{Conclusão}

Os dados obtidos validaram as hipóteses levantadas, pois inicialmente acreditava-se que os idosos teriam vida sexual ativa. Foi observado também que, diferente do que a população pensa, os idosos, em sua maioria, têm menos medo de expressar sua sexualidade na atualidade. Considerando tal cenário, percebe-se que a capacidade de se demonstrar sexualmente não é perdida ao longo do tempo, ela apenas se modifica, visto que grande parte dos idosos continua com a vida sexual ativa.

Falar sobre a sexualidade na terceira idade ainda é um tabu para a sociedade. A ideia de que a prática sexual é mais vivida durante a flor da idade e que com o passar dos anos se torne impraticável pelos idosos, equivocadamente faz parte do pensamento de boa parte da sociedade.

Apesar do histórico cultural que se envolve simbolicamente no preconceito e exclusão, os dados sobre a epidemia de HIV/AIDS e outras ISTs têm ganhado bastante notoriedade e isso se explica pelo fato de que até mesmo os profissionais de saúde se esquivam da ideia de que são pessoas que ainda possuem vida sexual ativa, deixando a desejar nas promoções de saúde para essa população específica, alimentando nessas pessoas uma imagem de que são isentos dos cuidados na hora da prática sexual.

Sendo assim, é notória a percepção dos idosos sobre a sexualidade possuir algumas limitações, desde a jovialidade até a atualidade. Entretanto, os idosos possuem vida sexual ativa, necessitando que os profissionais de saúde ajam de maneira multiplicadora do conhecimento de práticas seguras no cuidado e que promovam a saúde junto à sexualidade da população idosa. Cabe salientar que, para que haja mudanças das ideias pré-formadas e discussões sobre diversos aspectos inerentes a sexualidade e o ato sexual no envelhecimento, mais pesquisas precisam ser desenvolvidas, a fim de prestar um atendimento humanizado, com visão holística e livre de preconceitos.

\section{Potencial conflito de interesse}

Não há conflito de interesse

Fontes de financiamento

Não houve fontes de financiamento

\section{Contribuição dos autores}

Concepção e desenho da pesquisa: Lima AC, Pegoraro VA; Coleta de dados: Lima AC; Análise e interpretação dos dados: Lima AC, Alves JAR, Ferreira BM, Silva TP, Santos BMP, Reis RC, Pegoraro VA; Redação do manuscrito: Lima AC, Alves JAR, Ferreira BM, Silva TP, Santos BMP, Reis RC, Pegoraro VA 
1. Salgado AGAT, Araújo LF, Santos JVO, Jesus LA, Fonseca LKS, Sampaio DS. Velhice LGBT: uma análise das representações sociais entre idosos brasileiros. Ciências Psicológicas [Internet] 2017 [cited 2021 Dec 12];11;2(11):155-63. Disponível em: https://www.redalyc.org/articulo.oa?id=459553539006

2. Oliveira AS. Transição demográfica, transição epidemiológica e envelhecimento populacional no Brasil. Hygeia - Revista Brasileira de Geografia Médica e da Saúde 2019;15(32):69-79. doi: 10.14393/Hygeia153248614

3. IBGE - Instituto Brasileiro de Geografia e Estatística. Projeção da população do Brasil e das Unidades da Federação. 2018. [Internet]. [cited 2021 Dec 16]. Disponível em: https://www.ibge.gov.br/

4. Freitas MC, Queiroz TA, Sousa JAV. O significado da velhice e da experiência de envelhecer para os idosos. Rev Esc Enferm 2010;44(2):407-12. doi: 10.1590/S008062342010000200024

5. Yared YB, Melo SMM. Opção sexual ou orientação sexual? A compreensão de professores de um curso de Medicina sobre sexualidade. Rev Port Educ 2018;31(2):175-95. doi: 10.21814/rpe.15350

6. Gomes RM, Cidreira JM, Santos MCQ, Bastos NLMV, Santos KA, Santos MLQ. Sexualidade na terceira idade: as Representações sobre o sexo. Id on Line Rev Mult Psic 2018;12(40): 939-55. doi: 10.14295/idonline.v12i40.1168

7. Lima ICC, Fernandes SLR, Miranda GRN, Guerra HS, Loreto RGO. Sexualidade na Terceira idade e educação em saúde: um relato de experiência. R Saúde Públ Paraná 2020;3(1):137-43. doi: 10.32811/25954482-2020v3n1p137

8. Cunha LA, laniski VB, Pinheiro J, Goldim JR. O Processo de envelhecimento de idosos homossexuais. Rev Sorbi [Internet] 2018;6(1):36-56. Available from: http://www.sorbi.org.br/revista/index.php/revista_sorbi/article/view/61

9. Silva RM, Rodrigues BB, Gonçalves LS. A sexualidade na terceira idade sob a perspectiva dos idosos atendido num ambulatório de psicogeriatria do Distrito Federal. Braz J Develop 2020;6(2):6273-92. doi: 10.34117/bjdv6n2-071

10. Bell S, Reissing ED, Henry LA, VanZuylen $H$. Sexual activity after 60 : a systematic review of associated factors. Sex Med Rev 2017;5(1):52-80. doi: 10.1016/j.sxmr.2016.03.001

11. Cogo SB, Silva LMC, Martins LM, Alves AJP, Xavier ALM, Ruppelt BC, et al. Ações de extensão sobre a sexualidade e infecções sexualmente transmissíveis aos idoso: relato de experiência. Revista Eletrônica Acervo Saúde 2020;12(12):1-6. doi: 10.25248/reas.e4940.2020 
12. Gois AB, Santos RFL, Silva TPS, Aguiar VFF. Percepção do homem idoso em relação a sua sexualidade. Enferm Foco [Internet] 2017 [cited 2021 Dec16];8(3):14-8. Available from: http://revista.cofen.gov.br/index.php/enfermagem/article/view/1024/392

13. Santos AD, Santos ALS, Andrade LM, Sorte ETB, Santos ES, Guerra SS. Concepção de mulheres idosas sobre a sexualidade na velhice. Rev Enferm UFPE online 2019;13:1-8. doi: 10.5205/1981-8963.2019.241752

14. Reis SMAO, Meira AMT, Moitinho CR. História de vida de idosos no ensino superior: percursos inesperados de longevidade escolar. Revista Exitus 2018;8(3):340-69. doi: 10.24065/2237-9460.2018v8n3ID649

15. Brasil. Lei oㅜ 10.741, de 1 de outubro de 2003. Dispõe sobre o Estatuto do Idoso e dá outras providências sobre a pessoa idosa. Diário Oficial da União. 10 mar 2003. [Internet] [cited 2021 Dec 16]. Available from: http://www.planalto.gov.br/ccivil_03/leis/2003/l10.741.htm

16. Santos MC, Nunes R, Cruz GHS, Souza MS, Barbosa RAA, Lima ER, et al. Percepções e vivências de idosos sobre sua sexualidade. Almanaque Multidisciplinar de Pesquisa [Internet]. 2017 [cited 2021 Dec 16];1(1):25-36. Available from: http://publicacoes.unigranrio.edu.br/index.php/amp/article/view/4317

17. Souza CL, Gomes VS, Silva RL, Silva ES, Alves JP, Santos NR, et al. Aging, sexuality and nursing care: the elderly woman's look. Rev Bras Enferm 2019;72(2):71-78. doi: 10.1590/0034-7167-2018-0015

18. Aguiar RB, Leal MCC, Marques APO. Conhecimento e atitudes sobre sexualidade em pessoas idosas com HIV. Ciênc Saúde Coletiva 2020;25(6):2051-62. doi: 10.1590/1413-81232020256.18432018

19. Peixer TC, Ceolin T, Grosselli F, Vargas NRC, Casarin ST. Sexualidade na terceira idade: percepção de homens idosos de uma estratégia de saúde da família. J Nurs Health 2019;5(2):131-40. doi: 10.15210/jonah.v5i2.4681

20. Araújo BJ, Sales CO, Cruz LFS, Moraes-Filho IM, Santos OP. Qualidade de vida e sexualidade na população da terceira idade de um centro de convivência. Rev Cient Sena Aires [Internet]. 2017 [cited 2021 Dec 16];6(2):85-94. Available from: http://revistafacesa.senaaires.com.br/index.php/revisa/article/view/282/183

21. Andrade J, Ayres JA, Alencar RA, Duarte MTC, Parada CMG. Vulnerabilidade de idosos a infecções sexualmente transmissíveis. Acta Paul Enferm 2017;30(1):8-15. doi: 10.1590/1982-0194201700003

22. Sinkovic M, Towler L. Sexual aging: a systematic review of qualitative research on the sexuality and sexual health of older adults. Qual Health Res 2018;29(9):1239-54. doi: 10.1177/1049732318819834

23. Pinto MXR, Reis LA, Santana ES, Reis LA. Sexualidade e envelhecimento: a percepção de idosos participantes de grupo de convivência. Fisioter Bras 2019;20(1):43-49. doi: 10.33233/fb.v20i1.2386 
24. Srinivasan S, Glover J, Tampi RR, Tampi DJ, Sewell DD. Sexuality and the older adult. Curr Psychiatry Rep 2019;97(10):14-21. doi: 10.1007/s11920-019-1090-4 